\title{
On the identification of some Entamoeba species. Comments on
}

\section{a recent paper}

In our opinion, the recent article by Clark et al. (2006) on the phylogeny of Entamoeba species by genetic analysis contributes more confusion than clear insights to the systematics of this genus, especially in relation to Entamoeba equi and Entamoeba struthionis.

Trophozoites and four-nucleated cysts of $E$. equi were described by Fantham (1921) from two horses with intestinal disturbance. No cysts were found in the horse stool sample analysed by Clark et al. (2006) and there is no description of the trophozoites found in culture [the paper they refer to (Clark \& Diamond, 2002) is only a revision of culture methods]. It is impossible to confirm whether or not these trophozoites are compatible with Fantham's description or whether they really form four-nucleated cysts. Furthermore, despite environmental contamination being detected in the sample (Colpodella spp. were also found), the authors did not explain why this possibility was not taken into consideration for the Entamoeba trophozoites (especially when no cysts were found in the sample). In our opinion, the only valid identification that applies is Entamoeba sp., and the genetic characterization and validation of E. equi should wait until new isolates are obtained.

In relation to E. struthionis, its differential morphological, biological (Martínez-Díaz et al., 2000) and genetic (Ponce-Gordo et al., 2004) characteristics have been ignored by Clark et al. (2006) on the basis that a partial sequence of the small-subunit rRNA gene of a pig isolate 'showed close similarity to $E$. polecki and it is one of those genetic variants of Entamoeba polecki the existence of which 'has become clear'. However, there is no such close similarity, and E. polecki genotype variants have not been described. There are 36 differences (including base substitutions and deletions) in the partial sequence between E. struthionis and $E$. polecki (39 between the pig isolate and $E$. polecki), all of them located in the variable (taxonomic) regions of the gene. A comparable degree of dissimilarity is found in other Entamoeba species comparisons, such as Entamoeba chattoni-E. polecki (45 differences along the same fragment), $E$. chattoni-E. struthionis (48 differences) or Entamoeba histolytica-Entamoeba dispar (22 differences). With respect to the existence of genetic variants in E. polecki, this could also apply to E. struthionis, where not only genetic but also morphological differences are documented. Anyway, no genetic variants in E. polecki have been described to date. The references the authors give to demonstrate the existence of such variants are incorrectly used; Verweij et al. (2001) described two unidentified genotypes of one-nucleated cyst-forming Entamoeba from human samples as $E$. polecki-like (but not as E. polecki genotypes), and Blessmann et al. (2002) carried out an epidemiological study in which E. polecki (or other one-nucleated cyst-forming Entamoeba species) was not considered at all. In our opinion, the only relevant information from the article of Clark et al. (2006) in relation to $E$. struthionis is the detection of the species in a pig; however, as this observation was made in one sample from one pig, a spurious parasitosis cannot be ruled out on the basis of the data available.

\section{F. Ponce-Gordo ${ }^{1}$} and R. A. Martínez-Díaz ${ }^{2}$

${ }^{1}$ Departamento de Parasitología,
Facultad de Farmacia, Universidad Complutense de Madrid, Plaza Ramón y Cajal s/n, 28040 Madrid, Spain

${ }^{2}$ Departamento de Medicina Preventiva, Salud Pública y Microbiología, Facultad de Farmacia, Universidad Autónoma de Madrid, Av. Arzobispo Morcillo s/n, 28029 Madrid, Spain

\section{Correspondence: F. Ponce-Gordo (pponce@farm.ucm.es)}

Blessmann, J., Van Linh, P., Nu, P. A., Thi, H. D., Muller-Myhsok, B., Buss, H. \& Tannich, E. (2002). Epidemiology of amebiasis in a region of high incidence of amebic liver abscess in central Vietnam. Am J Trop Med Hyg 66, 578-583.

Clark, C. G. \& Diamond, L. S. (2002). Methods for cultivation of luminal parasitic protists of clinical importance. Clin Microbiol Rev 15, 329-341.

Clark, C. G., Kaffashian, F., Tawari, B., Windsor, J. J., Twigg-Flesner, A., Davies-Morel, M. C. G., Blessmann, J., Ebert, F., Peschel, B. \& other authors (2006). New insights into the phylogeny of Entamoeba species provided by analysis of four new small-subunit rRNA genes. Int J Syst Evol Microbiol 56, 2235-2239.

Fantham, H. B. (1921). Some parasitic protozoa found in South Africa: IV. South Afr J Sci 17, 164-170.

Martinez-Díaz, R. A., Herrera, S., Castro, A. \& Ponce, F. (2000). Entamoeba sp.

(Sarcomastigophora: Endamoebidae) from ostriches (Struthio camelus) (Aves: Struthionidae). Vet Parasitol 92, 173-179.

Ponce-Gordo, F., Martínez-Díaz, R. A. \& Herrera, S. (2004). Entamoeba struthionis n. sp. (Sarcomastigophora: Endamoebidae) from ostriches (Struthio camelus). Vet Parasitol 119, 327-335.

Verweij, J. J., Polderman, A. M. \& Clark, C. G. (2001). Genetic variation among human isolates of uninucleated cyst-producing Entamoeba species. J Clin Microbiol 39, 1644-1646. 